\title{
Pengaruh Motivasi Kerja Terhadap Kinerja Pegawai PT. Bank BJB Tbk. Cabang Karawang
}

\author{
Cindy Monica, Karyaningsih \\ Universitas Singaperbangsa Karawang, Jawa Barat \\ Cindy.monica@studentunsika.ac.id ${ }^{1}$, karyamada26@gmail.com ${ }^{2}$
}

\begin{abstract}
Abstrak
Penelitian ini bertujuan untuk mengetahui Pengaruh Motivasi Kerja Terhadap Kinerja Pegawai. Teknik pengambilan sampel menggunakan total sampling $(n=26)$, dan teknik analisis data menggunakan analisis korelasi dan analisis regresi linier sederhana dengan program SPSS Versi 20. Hasil rekapitulasi skor jawaban responden mengenai motivasi kerja sebesar 1.261, data tersebut berada pada tingkat baik, $(975-1267,5=$ setuju $)$ artinya bahwa motivasi kerja yang ada berada pada tingkat baik. Hasil analisis korelasi Motivasi Kerja Terhadap Kinerja Pegawai yaitu sebesar 0,732, nilai korelasi tersebut berada pada daerah kuat $(0,600-0,799=$ kuat). Nilai F hitung Motivasi Kerja $(X)$ lebih besar dari nilai $F$ tabel $(2227,756>4,26)$. Hasil analisis regresi linier model coefficients diperoleh persamaan yaitu $Y=14,817+0,740 X+$ e dari persamaan regresi tersebut dapat dideskripsikan bahwa nilai koefisien sebesar 14,817 adalah nilai koefisien kinerja pegawai $(\mathrm{Y})$ saat motivasi kerja $(\mathrm{X})$ sama dengan nol $(0)$ dan nilai sebesar 0,740 pada koefisien $X$ yaitu jika motivasi kerja $(X)$ naik sebesar 1 satuan unit skor, maka kinerja pegawai $(\mathrm{Y})$ naik sebesar 0,740 dengan asumsi faktor lain (e) konstan.
\end{abstract}

Kata kunci: motivasi kerja, kinerja pegawai

\begin{abstract}
The research aims to determine the effect of work motivation on employee performance. The sampling technique used total sampling $(n=26)$, and the data analysis technique use correlation analysis and simple linear regression analysis with the SPSS version 20 program. Good, $(975-126,5=$ agree) means that the existing work motivation is at a good level. The results of the correlation analysis of Work Motivation on Employee Performance amounting to 0,732 , the correlation value is in a strong area $(0,600-0,799=$ strong). The calculated $F$ value of Work Motivation $(X)$ is greater than the $\mathrm{F}$ table value $(2227,756>4,26)$. The results of linear regression analysis of the coefficients model obtained an equation, namely $Y=14,817+0,740 X+e$. OF 0,740 of 0,740 on the $X$ coefficient, that is, if work motivation $(X)$ increases by 1 unit score, the employee performance $(Y)$ increases by 0,740 assuming other factors e are constant.
\end{abstract}

Key words: work motivation, employee performance 
dapat merugikan perusahaan yang bersangkutan. Karena, begitu pentingnya motivasi bagi para pegawai, maka pimpinan dituntut untuk peka terhadap kepentingan dari

\section{PENDAHULUAN}

Dalam keadaan perekonomian yang semakin sulit ini banyak terjadi persaingan di berbagai bidang kehidupan. Termasuk di dalamnya persaingan dalam dunia bisnis. Banyak perusahaan yang saling berlomba untuk mendapatkan pangsa pasar, sehingga hal ini memacu perusahaan untuk berusaha terus maju dalam memperbaiki bisnisnya. Di samping itu dengan adanya kemajuan teknologi, perusahaan dituntut pula untuk dapat mengikuti perkembangan zaman agar tidak tertinggal dengan yang lainnya.

Supaya perusahaan dapat tumbuh dan berkembang dengan baik. Maka perusahaan tersebut harus dapat mengantisipasi perkembangan ekonomi yang semakin kompetitif dengan melakukan strategi yang tepat agar tidak tersisih dalam persaingan. Selain itu perusahaan juga harus dapat mengantisipasi kecenderungan ekonomi di masa mendatang dan harus dapat bersaing dengan perusahaan lain yang bergerak di bidang yang sama. Hal itu dilakukan untuk mempertahankan kelangsungan hidup dan kemajuan perusahaan.

Sumber daya manusia di dalam perusahaan mempunyai peranan yang sangat penting terutama dalam era pasar bebas sekarang ini. Dimana sumber daya manusia dewasa ini bukan dinilai sekedar asset utama saja melainkan asset yang bernilai dan dapat dilipatgandakan serta dapat dikembangkan. Dengan kata lain Sumber daya manusia yang berkualitas dan berkompeten merupakan salah satu asset yang harus dimiliki oleh suatu perusahaan.

Suatu perusahaan akan meningkat kinerjanya bila adanya kerjasama dan hubungan yang baik antara pimpinan dan pegawainya. Karena dengan meningkatnya kinerja pegawai otomatis akan meningkatkan kinerja perusahaan. Dan pegawai pun sebaiknya diperlakukan sebagai partner usaha dan bukan sebagai buruh semata.

Kinerja pegawai yang buruk dapat menimbulkan hal-hal yang tidak diinginkan dan para pegawainya. Disini pendekatan bukan hanya terhadap pegawai tetapi terhadap semua aspek yang berpengaruh terhadap motivasi dari pegawai itu sendiri. Sehingga pimpinan tahu apa yang menyebabkan pegawai termotivasi dalam bekerja. Jadi motivasi merupakan salah satu factor penentu dalam mencapai kinerja yang baik.

Motivasi merupakan hal yang sangat berpengaruh dalam pribadi para pegawai, karena akan meningkatkan kinerja pegawai itu sendiri. Maka motivasi merupakan hal yang sangat diharapkan sebuah perusahaan untuk mencapai tujuan perusahaan yang diinginkan.

Masalah kinerja pegawai atau pegawai bukanlah masalah yang sederhana, melainkan cukup kompleks, sehingga setiap perusahaan hendaknya memiliki pedoman atau standar yang jelas dalam menetapkan atau menilai kinerja dari para pegawainya karena kinerja pegawi tersebut dipengaruhi oleh banyak factor salah satunya adalah motivasi kerja dari pegawainya.

Bank merupakan salah satu perusahaan yang bergerak dalam bidang jasa. Perkembangan dunia perbankan saat ini menimbulkan yang sangat ketat antar bank untuk berkompetisi menarik nasabah dengan memberikan produk yang beranekaragam, selain itu juga dalam tahap pelayanannya. Kepuasan konsumen akan tercapai apabila kualitas produk dan jasa yang diberikan sesuai dengan kebutuhannya.

PT. Bank BJB Tbk, merupakan bank pemerintah milik daerah yang ada di Indonesia yang mempunyai peranan yang cukup besar dalam dunia perbankan. Kini PT. Bank BJB Tbk. Yang sudah Go Public terpacu untuk meningkatkan kinerjanya agar dapat unggul bersaing dengan bank-bank lainnya dalam memenuhi kebutuhan nasabahnya.

Berkaitan dengan pemaparan diatas, berdasarkan interview dan observasi awal diperoleh informasi bahwa pada PT. Bank BJB Tbk. Cabang Karawang terdapat beberapa hal yang menjadi permasalahan mengenai motivasi kerja pegawai dan kinerjanya. 
Berdasarkan data diatas penulis tertarik untuk melakukan penelitian dengan judul "Pengaruh Motivasi Kerja Terhadap Kinerja Pegawai pada PT. Bank BJB Tbk. Cabang Karawang."

Rumusan masalah penelitian ini adalah:

1. Bagaimana motivasi kerja pegawai pada PT. Bank BJB Tbk. Cabang Karawang?

2. Bagaimana kinerja pegawai pada PT. Bank BJB Tbk. Cabang Karawang?

3. Apakah terdapat pengaruh yang signifikan antara motivasi kerja terhadap kinerja pegawai pada PT. Bank BJB Tbk. Cabang Karawang?

Penelitian ini bertujuan untuk:

1. Untuk mengetahui bagaimana motivasi kerja pegawai pada PT. Bank BJB Tbk. Cabang Karawang.

2. Untuk mengetahui bagaimana kinerja pegawai pada PT. Bank BJB Tbk. Cabang Karawang.

3. Untuk mengetahui apakahterdapat pengaruh yang signifikan antara motivasi kerja terhadap kinerja pegawai pada PT. Bank BJB Tbk. Cabang Karawang.

Manfaat dalam penelitian ini sebagai berikut:

1. Manfaat Teoritis

a. Secara teoritis, diharapkan bermanfaat sebagai bahan untuk memperjelas konsep perihal kinerja pegawai.

b. Dengan mengenal pengaruh motivasi kerja terhadap kinerja pegawai, maka dapat dijadikan bahan pertimbangan dalam mengoptimalkan dan menetapkan kebijakan pegawai.

2. Manfaat Praktis

a. Bagi penulis, penelitian ini untuk mengaplikasikan ilmu teori yang telah diperoleh penulis selama proses perkuliahan serta untuk memenuhi salah satu persyaratan dalam menempuh ujian sidang sarjana ekonomi jurusan manajemen di Universitas Singaperbangsa Karawang.

b. Bagi perguruan tinggi, penelitian ini diharapkan dapat menjadi bahan referensi bagi rekan-rekan mahasiswa Unsika Singaperbangsa

Karawang, khususnya jurusan manajemen.

c. Bagi tempat penelitian, hasil penelitian diharapjan dapat memberikan sumbangan dalam aspek praktis (guna laksana) yaitu memberikan sumbangan pemikiran kepada manajemen PT Bank BJB Tbk. Cabang Karawang terhadap pengembangan ilmu, khususnya dalam menambah wawasan tentang manajemen sumber daya manusia.

d. Bagi peneliti, dapat menjadi masukan atau referensi bagi peneliti berikutnya.

\section{METODE}

Dalam menyelesaikan suatu permasalahan harus memakai cara atau metode tertentu yang sesuai dengan pokok permasalahan yang akan dibahas. Disamping itu, metode tersebut dipilih juga agar penelitian dapat menghasilkan data-data yang akurat dan dipercaya kebenarannya. Jenis penelitian yang penulis gunakan pada penelitian ini adalah jenis penelitian korelasi, metode korelasi ini sebenarnya adalah kelanjutan metode deskriptif. Pada metode deskriptif data dihimpun, disusun secara sistematis, factual dan cermat, namun tidak dijelaskan pengaruh antara variable dan tidak dilakukan uji atau prediksi (M. Iqbal Hasan, 2020:20) pada metode korelasi, pengaruh antar variable yang diteliti dan dijelaskan, pengaruh yang dicari ini disebut korelasi. Jadi metode korelasi untuk mencari pengaruh antara variable independen $\mathrm{X}$ terhadap variable dependen $\mathrm{Y}$.

Dalam penelitian ini yang menjadi variabel penelitian adalah Variabel motivasi kerja $(X)$ adalah menggunakan nilai skor yang diperoleh dari hasil pengukuran instrument berupa angket dengan 4 (empat) pilihan yakni : Sangat Setuju skor 1, Tidak Setuju skor 2, Kurang Setuju skor 3 setuju, Sangat Setuju 4. Variabel Motivasi Kerja (X) sebanyak 10 butir pernyataan tersebut disusun berdasarkan dimensi dan indicator. Sedangkan Kinerja Pegawai $(Y)$ adalah menggunakan skor yang diperoleh dari hasil pengukuran instrument berupa angket dengan 4 
(empat) pilihan jawaban yakni : Tidak Setuju skor 1, Kurang setuju skor 2, Setuju skor 3, Sangat Setuju skor 4. Variabel Kinerja Pegawai (Y) sebanyak 10 butir pernyataan tersebut disusun berdasarkan dimensi dan indicator.

\section{HASIL DAN PEMBAHASAN KARAKTERISTIK RESPONDEN}

Karakteristik menurut jenis kelamin terdiri dari 16 orang laki-laki dan 10 orang perempuan. Hal ini menunjukkan bahwa responden laki-laki jauh lebih banyak dibandingkan dengan responden perempuan. Menurut kelompok usia dapat dijelaskan bahwa responden berusia $<29$ Tahun sebanyak 8 orang, responden yang berusia 30-39 Tahun sebanyak 10 orang, dan responden berusia $>40$ Tahun sebanyak 7 orang. Hal ini menunjukkan bahwa responden terbanyak ialah yang berusia 30-39 Tahun. Berdasarkan tingkat pendidikan dapat dijelaskan bahwa tingkat pendidikan responden SMA/Sederajat sebanyak 9 orang, D3/S1 sebanyak 11 orang, S2 sebanyak 6 orang. Hal ini menunjukkan bahwa responden terbanyak adalah tingkat pendidikan D3/S1.

\section{UI KEABSAHAN DATA UJI VALIDITAS}

Menurut Sugiyono (2012), item yang mempunya korelasi positif dengan skor total serta korelasi tertinggi menunjukkan bahwa item tersebut dapat dianggap valid apabila $r=0,30$ sehingga apabila korelasi antar item dengan skor item total kurang dari 0,3 maka item instrument tersebut dinyatakan tidak valid.

1. Hasil uji validitas variabel motivasi kerja $(X)$, nilai $r$ hitung $>r$ table $(0,388)$ pada tabel 1 . Sehingga semua pernyataan adalah valid, dan dapat digunakan dalam penelitian.

Tabel 1. Hasil Uji Validitas Variabel Motivasi Kerja (X)

\begin{tabular}{cccc}
\hline Variabel & $\begin{array}{c}\mathbf{r} \\
\text { hitung }\end{array}$ & $\begin{array}{c}\mathbf{r} \\
\text { tabel }\end{array}$ & Keterangan \\
\hline Pernyataan 1 & 0,790 & 0,388 & Valid \\
Pernyataan 2 & 0,750 & 0,388 & Valid \\
Pernyataan 3 & 0,750 & 0,388 & Valid \\
Pernyataan 4 & 0,813 & 0,388 & Valid \\
Pernyataan 5 & 0,831 & 0,388 & Valid \\
Pernyataan 6 & 0,785 & 0,388 & Valid
\end{tabular}

$\begin{array}{cccc}\text { Pernyataan 7 } & 0,784 & 0,388 & \text { Valid } \\ \text { Pernyataan 8 } & 0,745 & 0,388 & \text { Valid } \\ \text { Pernyataan 9 } & 0,633 & 0,388 & \text { Valid } \\ \text { Pernyataan 10 } & 0,778 & 0,388 & \text { Valid }\end{array}$

Sumber: Diolah dari hasil penelitian SPSS, 2019

2. Hasil uji validitas variabel $Y$ (Kinerja Pegawai), nilai $r$ hitung $>r$ table $(0,388)$, pada table 2 . Sehingga masing-masing item adalah valid dan dapat digunakan dalam penelitian.

Tabel 2. Hasil Uji Validitas Variabel Kinerja Pegawai (Y)

\begin{tabular}{cccc}
\hline Variabel & $\begin{array}{c}\mathbf{r} \\
\text { hitung }\end{array}$ & $\begin{array}{c}\mathbf{r} \\
\text { tabel }\end{array}$ & Keterangan \\
\hline Pernyataan 1 & 0,790 & 0,388 & Valid \\
Pernyataan 2 & 0,750 & 0,388 & Valid \\
Pernyataan 3 & 0,813 & 0,388 & Valid \\
Pernyataan 4 & 0,831 & 0,388 & Valid \\
Pernyataan 5 & 0,785 & 0,388 & Valid \\
Pernyataan 6 & 0,784 & 0,388 & Valid \\
Pernyataan 7 & 0,745 & 0,388 & Valid \\
Pernyataan 8 & 0,633 & 0,388 & Valid \\
Pernyataan 9 & 0,778 & 0,388 & Valid \\
Pernyataan 10 & 0,750 & 0,388 & Valid \\
\hline \multicolumn{4}{l}{ Sumber: Diolah dari hasil penelitian SPSS, 2019 }
\end{tabular}

\section{UJI RELIABILITAS}

Uji reliabilitas guna untuk mengukur keakuratan, kestabilan dan konsistensi suatu instrument penelitian. Untuk menilai apakah reliable atau tidak instrument, dilakukan dengan mengkonsultasikan hasil perhitungan alpha cronbach dengan angka $r$ product moment. Jika diperoleh $r$ hitung (koefisien alpha cronbach) lebih besar dari pada $r$ table, maka instrument tersebut dinyatakan reliable. Sebaliknya jika $r$ hitung (koefisien alpha cronbach) lebih kecil dari $r$ table, maka instrument tersebut dinyatakan tidak reliable (Arikunto, 2010).

Menurut hasil uji reliabilitas pada penelitian ini didapat $r$ hitung (koefisien alpha cronbach) variabel Motivasi Kerja sebesar 0,933, variabel Kinerja Pegawai sebesar 0,933, maka nilai $r$ hitung (koefisien alpha cronbach) untuk tiap-tiap variabel lebih besar dari $r$ table $(0,60)$ sehingga variabel Motivasi Kerja (X), dan variabel Kinerja Pegawai $(\mathrm{Y})$ dinyatakan reliabel.

Berikut hasil uji reliabilitas variabel pada table 4 : 
Tabel 4. Hasil Uji Reliabilitas variabel $X$ dan $Y$

\begin{tabular}{lcccl}
\hline \multicolumn{1}{c}{ Variabel } & Cronbach's alpha & N of items & Alpha & Keterangan \\
\hline Motivasi Kerja $(\mathrm{X})$ & 0,933 & 10 & 0,60 & Reliabel \\
Kinerja Pegawai $(\mathrm{Y})$ & 0,933 & 10 & 0,60 & Reliabel \\
\hline
\end{tabular}

Sumber: Diolah dari hasil penelitian SPSS, 2019

$$
\begin{aligned}
& \text { Uji normalitas dilihat dengan uji kolmogrov } \\
& \text { smirnov, dimana nilai sig.>0,05: }
\end{aligned}
$$

\section{UJI ASUMSI KLASIK}

Tabel 5. Hasil Uji Normalitas One-Sample Kolmogorov-Smirnov Test

\begin{tabular}{|ll|r|}
\hline & & $\begin{array}{c}\text { Unstandardized } \\
\text { Residual }\end{array}$ \\
\hline $\mathrm{N}$ & Mean & 26 \\
Normal Parameters ${ }^{\mathrm{a}, \mathrm{b}}$ & Std. Deviation & .0000000 \\
& Absolute & 7.37027119 \\
Most Extreme Differences & Positive & .102 \\
& Negative & .068 \\
Kolmogorov-Smirnov Z & & .102 \\
Asymp. Sig. (2-tailed) & & .689 \\
\hline
\end{tabular}

Sumber: Diolah dari hasil penelitian SPSS, 2019

Dari Tabel 5, Nilai signifikannya $>0,05(0,730>\quad$ berdistribusi normal dan dapat digunakan dalam $0,05)$. Maka dapat disimpulkan jka data diatas penelitian.

\section{UJI MULTIKOLINIERITAS}

Tabel 6. Hasil Uji Multikolinieritas

\begin{tabular}{|c|r|r|}
\hline \multirow{2}{*}{ Model } & \multicolumn{2}{|c|}{ Collinearity Statistics } \\
\cline { 2 - 3 } & Tolerance & VIF \\
\hline Motivasi Kerja & .153 & \\
& & \\
\hline
\end{tabular}

Sumber: Diolah dari hasil penelitian SPSS, 2019

Dari Tabel 6. Nilai tolerance variabel Motivasi Kerja adalah 0,153>0,01 dengan nilai VIF tiap-tiap variabelnya: $(5,515)<10$. Maka dapat disimpulkan bahwa tidak terjadi multikolinieritas. 


\section{UJI REGRESI LINIER BERGANDA}

Analisis regresi linier berganda untuk mengukur pengaruh variabel bebas terhadap

$$
Y=14,817+0,740 X+e
$$

variabel terikat. Tabel 7 , yang persamaannya :

Tabel 7. Hasil Uji Regresi Linier Berganda

\begin{tabular}{|c|c|c|c|c|c|}
\hline \multirow[t]{2}{*}{ Model } & \multicolumn{2}{|c|}{$\begin{array}{c}\text { Unstandardized } \\
\text { Coefficients }\end{array}$} & $\begin{array}{c}\text { Standardized } \\
\text { Coefficients }\end{array}$ & $\mathrm{t}$ & Sig. \\
\hline & B & Std. Error & Beta & & \\
\hline (Constant) & 18.637 & 4.645 & & 4.012 & .000 \\
\hline Sumx1 & .725 & .316 & .730 & 2.295 & .027 \\
\hline
\end{tabular}

Sumber: Diolah dari hasil penelitian SPSS, 2019

Dengan keterangan sebagai berikut:

1. Besar konstanta 18,637 artinya apabila variabel Lingkungan Kerja (X1) dan Beban Kerja $(\mathrm{X} 2)=0$, maka $\mathrm{X} 1$ dan $\mathrm{X} 2$ berpengaruh positif terhadap kinerja karyawan.

2. Besar koefisien regresi variabel Lingkungan Kerja $(\mathrm{X} 1)=0,725$ artinya tiap kenaikan satu satuan variabel Lingkungan Kerja (X1), akan diikuti oleh Kinerja Guru sebesar 0,725 pula, dengan asumsi variabel bebas yang lain ialah tetap atau konsisten.

3. Koefisien regresi variabel Beban Kerja (X2), $=0,173$ artinta tiap kenaikan satu satuan variabel Beban Kerja (X2), akan diikuti oleh
Kinerja Guru sebesar 0,173 pula, dengan asumsi variabel bebas yang lain ialah tetap atau konsisten.

\section{KOEFISIEN DETERMINASI (R SQUARE)}

Nilai Koefisien Determinasi untuk memprediksi pengaruh variabel Lingkungan Kerja (X1) dan Beban Kerja (X2) terhadap variabel Kinerja Guru (Y), yang berada diantara 0 .

1. Berikut hasil uji Koefisien Determinasi tersebut pada tabel 8:

Tabel 8. Hasil Uji Determinasi (R Square)

\begin{tabular}{|c|c|c|c|c|c|c|}
\hline \multirow[b]{2}{*}{ Model } & \multirow[b]{2}{*}{$\mathrm{R}$} & \multirow[b]{2}{*}{ R Square } & \multirow[b]{2}{*}{$\begin{array}{l}\text { Adjusted R } \\
\text { Square }\end{array}$} & \multicolumn{3}{|c|}{ Change Statistics } \\
\hline & & & & $\begin{array}{c}\text { R Square } \\
\text { Change }\end{array}$ & F Change & Sig. F Change \\
\hline 1 & $.732^{\mathrm{a}}$ & .536 & .517 & .536 & 27.756 & .000 \\
\hline
\end{tabular}

a. Predictors: (Constant), Motivasi Kerja

Sumber: Diolah dari hasil penelitian SPSS, 2019 


\section{UJI HIPOTESIS}

Berdasarkan data pada tabel 8 tersebut diperoleh keluaran nilai koefisien korelasi (R) sebesar 0,732 atau $R>0$, artinya bahwa terdapat hubungan kuat $(0,600-0,799=$ kuat $)$ antara motivasi kerja dengan kinerja pegawai.

Hasil keluaran nilai koefisien determinasi $(\mathrm{R}$ square atau $R^{2}$ ) sebesar 0,538 atau $53,8 \%$. Nilai tersebut menunjukan kemampuan variabel motivasi kerja $(\mathrm{X})$ menjelaskan variansi pada variabel kinerja pegawai $(\mathrm{Y})$ sebesar $53,8 \%$ dan sisanya sebesar $46,2 \%$ dipengaruhi oleh faktor lain (e) yang tidak diikutsertakan dalam penelitian ini.
Uji hipotesis terdiri atas uji $\mathrm{F}$ dan uji t.

\section{Uji Simultas (Uji F)}

Uji $\mathrm{F}$ untuk mengamati variabel bebas Motivasi Kerja (X) secara bersamaan berpengaruh positif signifikan terhadap variabel terikat Kinerja Pegawai $(\mathrm{Y})$ yang terdapat pada tabel 9, berikut hasil uji simultan (Uji F) :

Tabel 9. Hasil Uji Simultan (Uji F)

ANOVA $^{\text {a }}$

\begin{tabular}{|ll|r|r|r|r|c|}
\hline Model & \multicolumn{1}{c|}{$\begin{array}{c}\text { Sum of } \\
\text { Squares }\end{array}$} & df & Mean Square & F & Sig. \\
\hline 1 & Regression & 454.294 & 1 & 454.294 & 27.756 & $.000^{\circ}$ \\
& Residual & 392.822 & 24 & 16.368 & & \\
& Total & 847.115 & 25 & & & \\
\hline
\end{tabular}

a. Dependent Variable: Kinerja

b. Predictors: (Constant), Motivasi Kerja

Sumber: Diolah dari hasil penelitian SPSS, 2019

Berdasarkan data pada tabel tersebut diperoleh nilai signifikansi $F$ sebesar 0,000 ( $P$ value) artinya bahwa variabel motivasi kerja $(X)$ berpengaruh sangat signifikan terhadap variabel kinerja pegawai (Y). atau dengan memperhatikan nilai $F$ hitung $(27,756)$ yang mempunyai nilai lebih besar dari nilai $F$ tabel $(4,26)$ atau 27,756 > 4,26 yang berarti bahwa variabel motivasi kerja $(X)$ berpengaruh sangat signifikan terhadap kinerja pegawai $(\mathrm{Y})$.

\section{Uji Parsial (Uji t)}

Uji parsial (uji t) untuk mengetahui apakah Motivasi Kerja (X) dan secara parsial berpengaruh signifikan terhadap Kinerja
Pegawai ( $Y$ ). dengan signifikansi kriteria uji $t$ berikut:

a. Nilai koefisien sebesar 14,817 adalah nilai koefisien kinerja pegawai $(\mathrm{Y})$ saat motivasi kerja $(\mathrm{X})$ sama dengan nol (0).

b. Nilai sebesar 0,740 pada koefisien $X$ yaitu jika motivasi kerja $(X)$ naik sebesar 1 satuan unit skor, maka kinerja pegawai (Y) akan naik sebesar 0,740 .

Berikut adalah tabel hasil uji t : 
Tabel 10. Hasil Uji Parsial (Uji t)

Coefficients $^{a}$

\begin{tabular}{|c|c|c|c|c|c|c|}
\hline \multirow{2}{*}{\multicolumn{2}{|c|}{ Model }} & \multicolumn{2}{|c|}{ Unstandardized Coefficients } & \multirow{2}{*}{$\begin{array}{c}\begin{array}{c}\text { Standardized } \\
\text { Coefficients }\end{array} \\
\text { Beta }\end{array}$} & \multirow[b]{2}{*}{$t$} & \multirow[b]{2}{*}{ Sig. } \\
\hline & & $\mathrm{B}$ & Std. Error & & & \\
\hline \multirow[t]{2}{*}{1} & (Constant) & 14.817 & 6.863 & & 2.159 & .041 \\
\hline & Motivasi Kerja & .740 & .141 & .732 & 5.268 & .000 \\
\hline
\end{tabular}

a. Dependent Variable: Kinerja

Dari tabel 10. Nilai signifikan Lingkungan Kerja : 0,000 $<0,05$, maka dapat disimpulkan bahwa variabel Motivasi Kerja $(X)$ berpengaruh signifikan terhadap Kinerja Pegawai $(\mathrm{Y})$.

\section{Pengaruh Motivasi Kerja Terhadap Kinerja Pegawai}

Berdasarkan hasil perhitungan Uji Parsial (Uji t), variabel Motivasi Kerja $(X)$ bernilai signifikan $0,000<0,05$. Maka dapat disimpulkan bahwa Motivasi Kerja di Bank BJB Tbk. Cabang Karawang sangat berpengaruh penting terhadap kinerja Pegawai.

\section{SIMPULAN}

Menurut penelitian yang sudah dikerjakan maka kesimpulan yang dapat diambil mengenai Motivasi Kerja terhadap Kinerja Pegawai di PT. Bank BJB Tbk. Cabang Karawang sebagai berikut:

1. Motivasi Kerja yang ada pada PT. Bank BJB Tbk. Cabang Karawang berada pada tingkat baik. Hal tersebut berdasarkan dari nilai rekapitulasi jawaban responden mengenai motivasi kerja yaitu sebesar 1.261 (975 126,7 = setuju).

2. Kinerja pegawai pada PT. Bank BJB Tbk.Cabang Karawang berada pada tingkat sangat baik. Hal tersebut berdasarkan dari nilai rekapitulasi jawaban responden mengenai kinerja pegawai yaitu sebesar $1.319(1267,5-1560=$ sangat setuju $)$.

3. Motivasi kerja berpengaruh sangat signifikan terhadap kinerja pegawai. Keadaan ini ditunjukan dari nilai $\mathrm{F}$ hitung lebih besar dari $F$ tabel $(27,756>4.26)$ dengan tingkat signifikan $\mathrm{F}$ lebih kecil dari nilai alpha $(0,000<0,05)$ atau juga ditunjukan dari nilai t hitung lebih besar dari $t$ tabel $(5,268>2,063)$ dengan tingkat signifikan $\mathrm{t}$ lebih kecil dari nilai alpha $(0,000$ $<0,05)$.

\section{DAFTAR PUSTAKA}

1. Arikunto, S. (2010). Prosedur Penelitian:

Suatu Pendekatan Praktik. Jakarta: Bineka Cipta.

2. Lysaght, R., Fabrigar, L., Larmour-Trode, S., Stewart, J., \& Friensen, M. (2012). Measuring workplace social support for workers with disability. Journal of Occupational Rehabilitation, 22 (3), 376-386.

\section{https://doi.org/10.1007/s10926-012-} 9357-1

3. Mangkunegara, A. A. P. (2017). Manajemen Sumber Daya Manusia (Bandung). Remaja Rosdakarya.

4. Mardiana, M. (2011). Manajemen Produksi. Jakarta: Badan Penerbit IPWI.

5. Sugiyono. (2012). Statistika Untuk Penelitian. Bandung: Alfabeta.

6. Sutrisno. 2012. Manajemen Keuangan Teori, Konsep dan Aplikasi ( $8^{\text {th }}$ ed). Yogyakarta: Ekonisia. 